\title{
Advanced Tracheal Adenoid Cystic Carcinoma with Thyroid Invasion Mimicking Thyroid Cancer Treated with Definitive Radiation: Case Report and Review of the Literature
}

\author{
Sondos Al Khatib ${ }^{a}$ Wafa Asha ${ }^{a} \quad$ Omar Khzouz $^{b} \quad$ Farid Barakat $^{c}$ \\ Jamal Khader ${ }^{\mathrm{a}}$ \\ ${ }^{a}$ Department of Radiation Oncology, King Hussein Cancer Center, Amman, Jordan; \\ ${ }^{b}$ Department of Diagnostic Radiology, King Hussein Cancer Center, Amman, Jordan; \\ ${ }^{\mathrm{C}}$ Department of Pathology, King Hussein Cancer Center, Amman, Jordan
}

\section{Keywords}

Trachea $\cdot$ Adenoid cystic carcinoma $\cdot$ Thyroid

\begin{abstract}
A 54-year-old female patient, a breast cancer survivor and a case of unresectable adenoid cystic carcinoma of the trachea, with thyroid invasion, presented with suprasternal neck swelling mimicking thyroid primary. A literature search was undertaken to highlight this rare presentation. There have been few reports in the literature describing tracheal adenoid cystic carcinoma involving the thyroid.

(C) 2017 The Author(s)

Published by S. Karger AG, Basel
\end{abstract}

\section{Introduction}

Primary adenoid cystic carcinoma (ACC) of the trachea (TACC) with thyroid invasion is exceedingly rare. Furthermore, data addressing the optimal therapeutic strategy is limited. The classic management involves surgical resection and adjuvant radiation therapy [1]; for 
patients with unresectable, nonmetastatic TACC, there are few data to guide treatment. Either radiotherapy or combined chemoradiotherapy with a platinum-based regimen is an option based on experience from ACC of the head and neck [2].

\section{Case Report}

We report a case of a 54-year-old female patient with no history of smoking or alcohol use. A known case of right breast cancer, stage T3N0, diagnosed in 2006 at King Hussein Cancer Center (KHCC), Amman, Jordan, she was treated back then with modified radical mastectomy and adjuvant chemotherapy (4 cycles of doxorubicin, cyclophosphamide), with five years of hormonal therapy (tamoxifen), and no radiotherapy was needed. She was kept on follow-up, with no evidence of disease recurrence. In 2013, the patient was presented with suprasternal neck fullness, for which she was advised to do ultrasound-guided biopsy, but she decided not to, whereupon she was lost follow-up. She presented back in 2016, following worsening of her symptoms, with progression of fullness in the neck, dyspnea, and eventual dysphagia. On examination, the patient had a suprasternal neck mass $3 \times 3 \mathrm{~cm}$, nontender, fixed to the underlying structure, moving with the thyroid during swallowing, not attached to the skin, and without skin changes. Her investigations done at KHCC including neck ultrasound showed a left-sided solid soft tissue mass invading/arising from the left lobe of the thyroid gland. Clinical differential diagnosis included a secondary deposit, or primary thyroid cancer.

CT of the neck and chest showed a large heterogeneous soft tissue mass in the lower neck, inseparable from the left lobe of the thyroid gland, with retrosternal extension and shifting the trachea to the right side (Fig. 1, Fig. 2).

CT scan findings revealed a thyroid mass with mediastinal extension displacing aortic branches laterally that did not look like simple thyroid extension. Fine-needle aspiration was done and was inconclusive, so biopsy was performed. Thyroid biopsy was consistent with adenoid cystic cancer. The tumor cells were positive for S100 and C-kit (weak, focal). No thyroid tissue was seen in the material examined (Fig. 3a-d). The patient's case was discussed at our multidisciplinary team meeting with input from cardiothoracic surgery, medical oncology, radiation oncology, and the head and neck and thoracic team. The mass was deemed unresectable based on the imaging findings described above. Following discussion, the decision was made to treat the patient with definitive radiation and concurrent platinum-based chemotherapy, given the potential locoregional advantage its inclusion may afford [3]. The patient refused chemotherapy, so she received a radiotherapy course of $60 \mathrm{~Gy}$ over 30 fractions via 3-D conformal radiation therapy administered under the care of the radiation oncology team (Fig. 4a-d). No severe or serious adverse events were reported after completion of radiotherapy, apart from grade II skin reaction and mild dysphagia.

\section{Discussion}

Primary tracheal tumors are rare. Population-based studies report annual incidence rates of tracheal cancer of approximately 0.1 per 100,000 per year, with tracheal cancers accounting for less than $0.5 \%$ of all malignant tumors [3-6]. The largest reported series comes from a Surveillance, Epidemiology, and End Results (SEER) analysis of 578 cases of primary tracheal carcinoma identified over a 31-year period [7]. In that series, the median 


\section{Case Reports in Oncology}

age was 63 years, and $56 \%$ of patients were male. In regard to primary tracheal tumors, most tumors in adult patients are malignant, with approximately two-thirds being squamous cell carcinomas, while ACCs were the second most common, accounting for approximately $10-15 \%$ of cases $[3,5-8]$. As mentioned above, TACC is a rare entity, and only a few cases have been described, none as a second malignant neoplasm. To the best of our knowledge, this is the first report of a metachronous second primary TACC in a breast cancer survivor. Although the risks for the development of metachronous second malignancies are well described for survivors of childhood malignancies, there are fewer data in older adults [8]. Secondary solid malignancies in breast cancer survival (mainly lung cancer, esophageal cancer, and sarcoma [9-13]) are also more likely following radiation treatment for breast cancer, which our patient did not receive. Although the development of metachronus breast cancer after a history of primary salivary gland tumor, including ACC, had been implied in the literature [14], there has been no data describing TACC as a second malignant neoplasm in breast cancer survivors.

TACC diagnosis is often delayed, as symptoms are subtle and insidious, and they are often misdiagnosed tumors; they may not cause symptoms until they occlude $75 \%$ of the tracheal luminal diameter [15]. As the incidence of TACC is relatively low, TACC involving the thyroid, as in the case we present, is even rarer $[16,17]$. TACC involves the thyroid mainly through invasion via direct extension, and few cases present with metastasis [15]. Ten case reports of primary ACC with thyroid invasion included 4 male (40\%) and 6 female patients (60\%). Their ages ranged from 17 to 68 years, with the average age being 49.8 years. There were no current smokers among them. Of the 10 ACC cases, 6 primary tumors originated from the bronchi, 3 tumors originated from the laryngeal minor salivary glands, and 1 tumor originated from the left parotid gland. Respiratory symptoms were the main clinical presentation for all 10 patients. Four patients experienced dyspnea, 3 had cough, 2 experienced hoarseness, 2 developed asthma, 2 experienced wheezing, 1 had hemoptysis, 1 developed neck pain, and 1 had no symptoms at all. Of the 10 cases, 3 involved the left thyroid lobe, 6 involved both lobes, and 1 involved the thyroid isthmus. Metastases varied in size, with the largest being $8 \times 6 \times 5 \mathrm{~cm}$ and the smallest being $1.0 \times 0.7 \mathrm{~cm}$. Three patients had concomitant multiple metastases, which were located in the arytenoid and cricoid cartilage, lungs, muscle, and esophagus. Seven of 10 patients underwent radical resection, 1 patient underwent local excision, and 1 patient did not receive any surgery. In addition to surgical treatment, 3 patients received radiotherapy and 1 patient received radiotherapy and chemotherapy. Patient survival time varied greatly after metastasis. The shortest survival time was only 1 month, and the longest was $>48$ months. The prognosis of female patients seems better than that of male patients. Only 1 male case report provided the time interval between diagnosis and death. In this case, the patient died within a month after diagnosis, while all 6 female patients lived for $>3$ months [18].

Surgical excision remains the mainstay of treatment for primary TACC. The trachea is a fibroblastic tube supported by incomplete cartilaginous rings. The adult trachea has a mean length of $11 \mathrm{~cm}$ (cricoid to carina) with a range of 9-15 cm. The amount of trachea that can safely be excised varies substantially between patients. Young age, thin body habitus, and long neck are favorable patient factors for long tumors. Five to six centimeters is usually the maximal length that can be safely resected with a primary anastomosis [19]. Radiation therapy alone has poorer outcomes; however, this in part may be due to some selection bias, with more advanced tumors likely to be deemed unresectable [20]. For unresectable cases, proton irradiation [21] or high linear energy transfer with neutron or carbon ions has also shown promise as higher radiobiological effectiveness and added precision allow for higher 


\section{Case Reports in Oncology}

\begin{tabular}{l|l}
\hline Case Rep Oncol 2017;10:706-712 \\
\hline DOI: 10.1159/000479225 & $\begin{array}{l}\text { (c) 2017 The Author(s). Published by S. Karger AG, Basel } \\
\text { www.karger.com/cro }\end{array}$ \\
\hline
\end{tabular}

Al Khatib et al.: Advanced Tracheal Adenoid Cystic Carcinoma with Thyroid Invasion Mimicking Thyroid Cancer Treated with Definitive Radiation: Case Report and Review of the Literature

dose intensity [22]. These treatments are, however, limited by cost and availability. Combined chemoradiotherapy is, however, widely available. There is some evidence that concurrent chemoradiotherapy, especially with platinum-based chemotherapy, may have a role in improving locoregional control [3, 23-25].

\section{Conclusion}

TACC is a rare malignancy that is difficult to diagnose due to the nonspecific nature of the presenting symptoms. The tumor is often at an advanced stage at the time of diagnosis, rendering surgical resection infeasible, with the only option of radiotherapy with consideration of chemotherapy. Every case should be individualized, given the rare presentation and the limited data to guide the treatment. This disease remains a significant challenge as distant failure is independent of local control and there are few proven strategies of worth for disseminated disease.

\section{Statement of Ethics}

Patient consent was obtained.

\section{Disclosure Statement}

All authors have no conflicts of interest to declare.

\section{Author Contributions}

All authors drafted the manuscript, read, and approved the final manuscript.

\section{References}

1 Mendenhall WM, Morris CG, Amdur RJ, et al: Radiotherapy alone or combined with surgery for adenoid cystic carcinoma of the head and neck. Head Neck 2004;26:154

-2 Stannard C, Vernimmen F, Carrara H, et al: Malignant salivary gland tumours: can fast neutron therapy results point the way to carbon ion therapy? Radiother Oncol 2013;109:262-268.

-3 Licht PB, Friis S, Pettersson G: Tracheal cancer in Denmark: a nationwide study. Eur J Cardiothorac Surg 2001;19:339-345.

4 Nouraei SM, Middleton SE, Nouraei SA, et al: Management and prognosis of primary tracheal cancer: a national analysis. Laryngoscope 2014;124:145.

5 Manninen MP, Antila PJ, Pukander JS, Karma PH: Occurrence of tracheal carcinoma in Finland. Acta Otolaryngol 1991;111:1162.

-6 Honings J, van Dijck JA, Verhagen AF, et al: Incidence and treatment of tracheal cancer: a nationwide study in the Netherlands. Ann Surg Oncol 2007;14:968.

7 Urdaneta AI, Yu JB, Wilson LD: Population based cancer registry analysis of primary tracheal carcinoma. Am J Clin Oncol 2011;34:32.

8 Garden S, Weber RS, Morrison WH, Ang KK, Peters LJ: The influence of positive margins and nerve invasion in adenoid cystic carcinoma of the head and neck treated with surgery and radiation. Int J Radiat Oncol Biol Phys 1995;32:619-626.

-9 Rubino C, de Vathaire F, Shamsaldin A, et al: Radiation dose, chemotherapy, hormonal treatment and risk of second cancer after breast cancer treatment. Br J Cancer 2003;89:840-846. 


\section{Case Reports in Oncology}

\begin{tabular}{l|l}
\hline Case Rep Oncol 2017;10:706-712 \\
\hline DOI: 10.1159/000479225 & $\begin{array}{l}\text { (c) 2017 The Author(s). Published by S. Karger AG, Basel } \\
\text { www.karger.com/cro }\end{array}$ \\
\hline
\end{tabular}

Al Khatib et al.: Advanced Tracheal Adenoid Cystic Carcinoma with Thyroid Invasion Mimicking Thyroid Cancer Treated with Definitive Radiation: Case Report and Review of the Literature

10 Berg JW, Hutter RVP, Foote FW Jr: The unique association between salivary gland cancer and breast cancer. JAMA 1968;204:771-774.

11 VanderWalde AM, Hurria A: Second malignancies among elderly survivors of cancer. Oncologist 2011;16:1572-1581.

-12 Kirova YM, Vilcoq JR, Asselain B, et al: Radiation-induced sarcomas after radiotherapy for breast carcinoma: a large-scale single-institution review. Cancer 2005;104:856-863.

-13 Abbey LM, Schwab BH, Landau GC, et al: Incidence of second primary breast cancer among patients with a first salivary gland tumor. Cancer 1984;54:1439-1442.

14 Idowu MO, Reiter ER, Powers CN: Adenoid cystic carcinoma: a pitfall in aspiration cytology of the thyroid. Am J Clin Pathol 2004;121:551-556.

15 Zirkin HJ, Tovi F: Tracheal carcinoma presenting as a thyroid tumor. J Surg Oncol 1984;26:268-271.

-16 Lee MW, Batoroev YK, Odashiro AN, Nguyen GK: Solitary metastatic cancer to the thyroid: a report of five cases with fine-needle aspiration. Cytojournal 2007;4:5.

17 Qi D, Feng L, Li J, Liu B, Zhang Q: Primary adenoid cystic carcinoma of the trachea with thyroid invasion: a case report and literature review. Onco Targets Ther 2016;9:6291-6296.

18 Gaissert HA, Mark EJ: Tracheobronchial gland tumors. Cancer Control 2006;13:286-294.

19 Grillo HC, Mathisen DJ, Wain JC: Management of tumors of the trachea. Oncology 1992;6:61-72.

-20 Primov-Fever A, Talmi YP, Yellin A, Wolf M: Cricotracheal resection for airway reconstruction: the Sheba Medical Center experience. Isr Med Assoc J 2006;8:543-547.

-21 Chen AM, Bucci MK, Weinberg V, et al: Adenoid cystic carcinoma of the head and neck treated by surgery with or without postoperative radiation therapy: prognostic features of recurrence. Int J Radiat Oncol Biol Phys 2006;66:152-159.

22 Bonner Millar LP, Stripp D, Cooper JD, Both S, James P, Rengan R: Definitive radiotherapy for unresected adenoid cystic carcinoma of the trachea. Chest 2012;141:1323-1326.

-23 Maruya S, Namba A, Matsubara A, et al: Salivary gland carcinoma treated with concomitant chemoradiation with intraarterial cisplatin and docetaxel. Int J Clin Oncol 2006;11:403-406.

-24 Samant S, van den Brekel MW, Kies MS, et al: Concurrent chemoradiation for adenoid cystic carcinoma of the head and neck. Head Neck 2012;34:1263-1268.

-25 Matsuba HM, Spector GJ, Thawley SE, Simpson JR, Mauney M, Pikul FJ: Adenoid cystic salivary gland carcinoma: a histopathologic review of treatment failure patterns. Cancer 1986;57:519-524
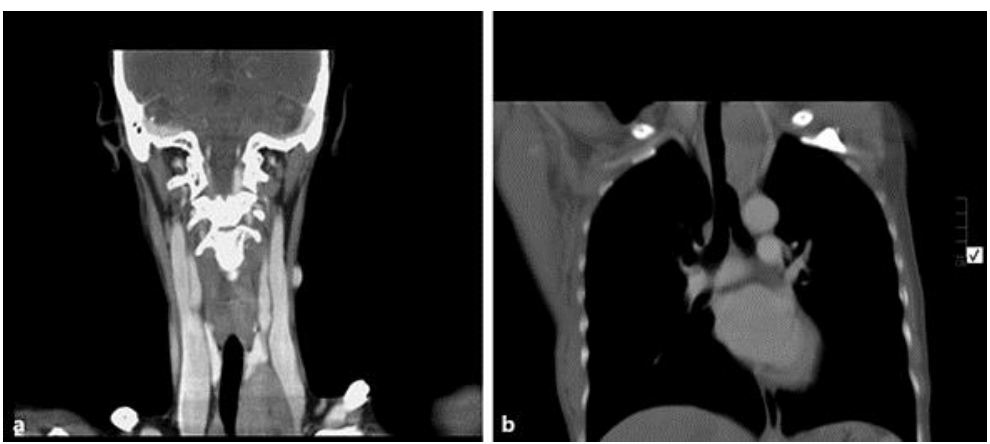

Fig. 1. Coronal neck CT scan (a) and coronal thorax post-contrast (b) of the patient showing a left paratracheal mass extending to the neck. 


\section{Case Reports in Oncology}

Al Khatib et al.: Advanced Tracheal Adenoid Cystic Carcinoma with Thyroid Invasion Mimicking Thyroid Cancer Treated with Definitive Radiation: Case Report and Review of the Literature
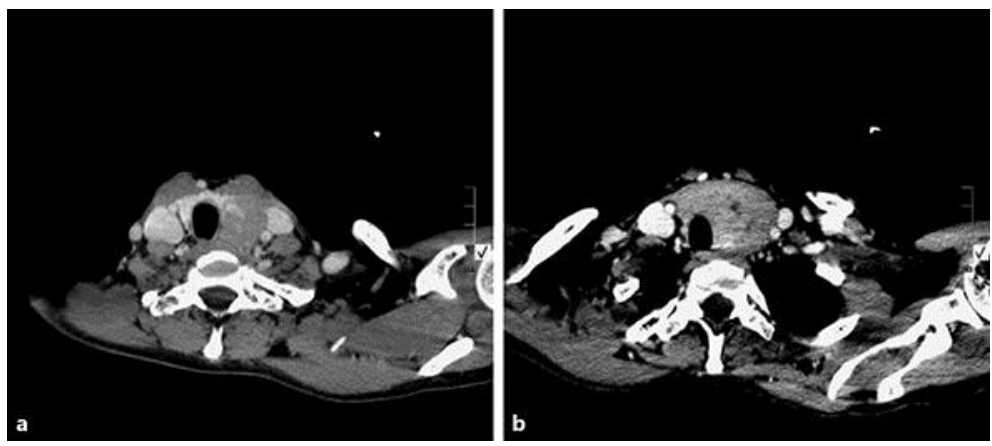

Fig. 2. Axial neck CT post-contrast showing a heterogeneous soft tissue mass invading the left thyroid lobe $(a, b)$.

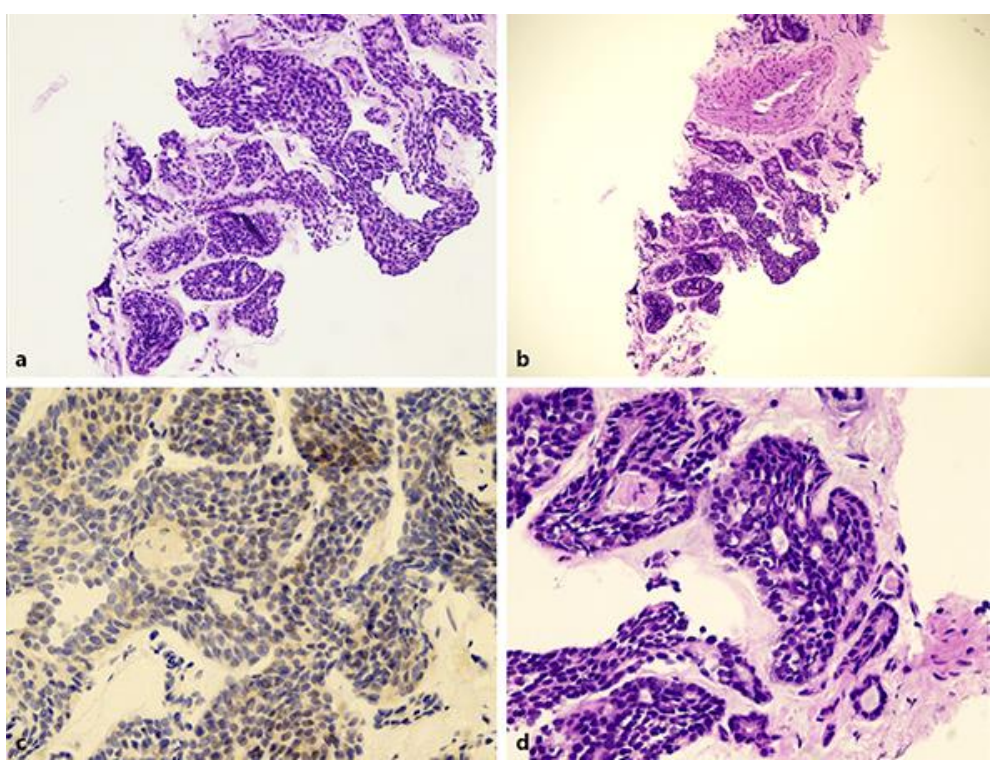

Fig. 3. Sections show a moderately cellular tumor composed of rounded to polygonal cells (a) that form small cystic spaces. Some spaces appear to be lined by cuboidal cells, while other spaces appear to be punched out (b). There is no necrosis in the background. Mitotic rate is low. No vascular or perineural invasion is seen (c). Tumor cells are positive for CD117 (C-kit) (d). 


\section{Case Reports in Oncology}
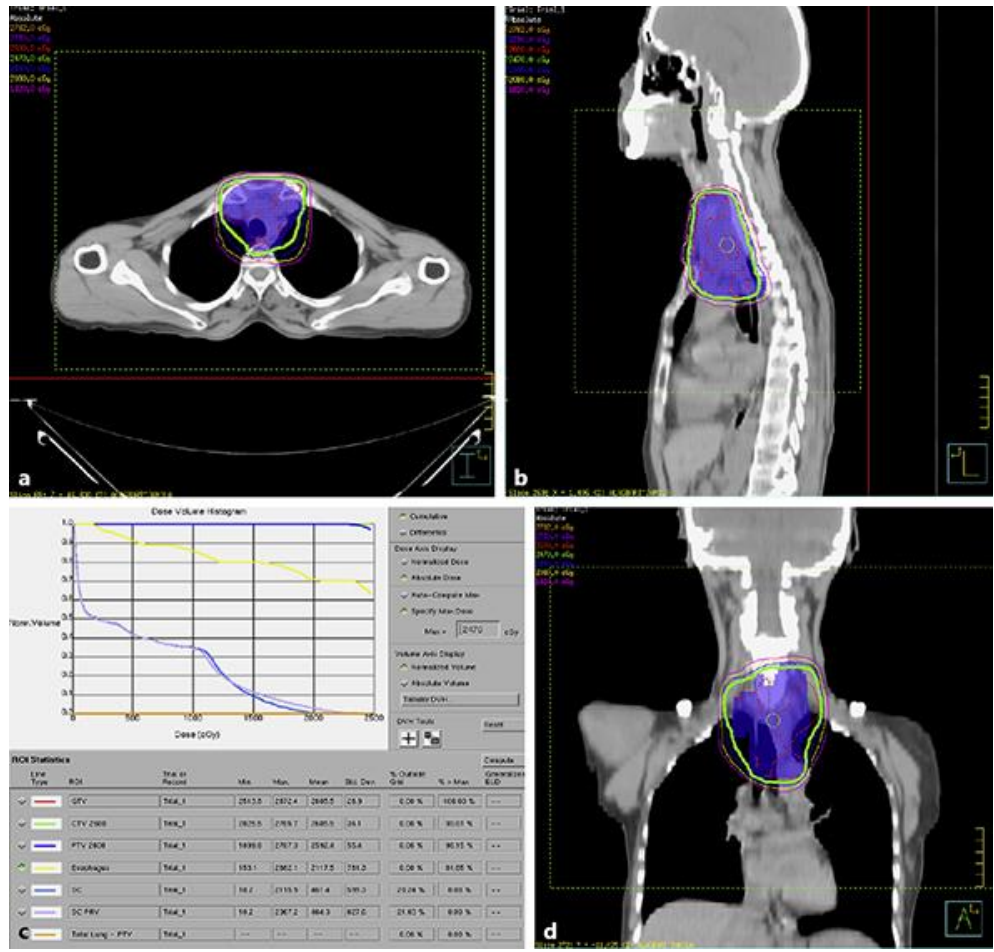

Fig. 4. Images of the patient treatment plan. Axial (a), sagittal (b), and coronal section (d), and dose volume histogram (c). 